\title{
Research on the Risk Spillover Effect of Iron Ore Futures Market
}

\section{Yong Wang}

\author{
School of finance, Zhejiang University of Finance \& Economics, Hangzhou 310018, China \\ upcnku@163.com
}

\section{Keywords: Iron ore futures; Effect of risk spillover; Pricing power}

\begin{abstract}
Iron ore is very important to China's steel industry and the whole national economy. Studying the risk of overflow relationship and the transfer of pricing power between international and domestic iron ore futures has great influence on China's economy. Spillover effects of financial market risk research methods and the futures market risk spillover effect results are analyzed and reviewed in this paper, it is concluded that the present situation of research literature summary appearing in some risk spillover results at home and abroad mainly focused on the stock market, bond market and bank financial markets, and research on commodity futures market risk spillover is relative shortage. In the future, the research on the risk spillover and pricing transfer of financial markets can focus on commodity futures market, especially in the direction of iron ore futures.
\end{abstract}

\section{Introduction}

With the development of economic globalization, the world economy is becoming more and more integrated, and financial markets are becoming more and more interconnected. Facts have proven that a financial market volatility is not confined to its own factors, also may be affected by other financial markets, the risk in the transfer between different financial institutions and financial markets effect is financial risk spillover effect. And the risk spillover effect of futures market mainly refers to the risk from developed futures market to other less developed futures markets. If about a financial variables, the degree of overflow of the positive risk spillover of a financial markets to the other financial markets is large, then the market financial variables have certain pricing power, which can lead the other markets. A review of previous studies shows that there is a risk spillover effect between financial markets.

The steel industry is the basic industry of our economy, and the demand for iron ore is increasing year by year. However, the supply of iron ore in China is far behind the steel production capacity, and the external dependence is higher, and shortage of the effective supply of domestic iron ore resources is the established fact. Since 2003, 88 per cent of the world's new iron ore has been bought by the steel companies in China, and its imports have far exceeded that of Japan, which has become the largest importer of iron ore. From 2007 to 2008, China accounted for more than 50\% of the total steel imports in the international market, and the external dependence of iron ore reached 52.5\%. In 2009 and 2016, China's iron ore that be imported reached 70 percent, which made our steel enterprises always in a disadvantage in the price negotiation with international iron ore suppliers.

China is pushing for "pricing power" for China's iron ore futures. The fluctuation of iron ore price will directly affect our national economy. (1) The rise in iron ore prices will directly reduce the profits of the steel industry. (2) It aggravates the predatory exploitation of iron ore resources by mine enterprises in China. (3) The transmission effect of iron ore price will increase the production cost of China's steel industry. (4) Rising iron ore prices will affect other imported raw materials pricing.

In this context, iron ore is very important to China's steel industry and even to the whole national economy. The study of pricing power of iron ore has a far-reaching impact on China's national economy. But for now, there are not much papers about the international and domestic iron ore futures and futures, the risk of overflow relationship between futures and spot research achievements and the effect of changes in iron ore pricing power. This paper aims at studying the financial market risk of overflow research results and the risk of futures industry related futures 
varieties overflow results for generalized comb, further to study iron ore futures market to carry on the beneficial supplement, and hope to provide certain theoretical reference for the future research scholar research related industries.

\section{Analysis of Research Methods of Risk Spillover Effect}

In 1990, the risk premium model of volatility was first proposed in the analysis of the spillover effects between different stock markets. John (2012) [1] pointed out that how to profit from commodity futures trading, and had a guiding significance for practical investment activities. Subsequently, more and more scholars used different measurement models to study the risk spillover analysis between different financial markets. This paper reviews the empirical model methods widely used by domestic and foreign scholars, and divide the research achievements of related risks into the following five categories.

Research Based on VaR Model. Russo (2009) [2] presented an extended model for calculating $\mathrm{VaR}$, and evaluated the predication of four conditional moments, such as mean, volatility, kurtosis and skewness. Based on VaR model, Ning Du and Guangwen Zhang (2011) [3] had studied the price discovery of soybean futures market and concluded that there was an overflow relationship between soybean futures and spot prices.

Research Based on Granger Causality Test Model. Rajput et al. (2012) [4] used Granger causality test to study the relationship between information spillovers and volatility spillovers in Indian stock markets in 1992-2011. Yitian Pu (2016) [5] studied the long-term co-integration relationship between non-ferrous metal futures market and corresponding stock market by using Granger causality test, and the spillover effect between them was analyzed.

Research Based on Garch Model. Sadorsky (2012) [6] applied correlation multivariate GARCH model to build conditions, analysis of oil and clean energy companies and technology between the stock price volatility spillover, to find the most suitable for dynamic conditions related to model data, and produce results, showed that clean energy company's stock price compared with the technology shares, associated with oil. Zhenxin Wu (2016) [7] respectively based on normal distribution, $t$ distribution, GED distribution under the assumption of EGARCH model, inspected EUA and CER futures returns volatility characteristics, and estimated the risk VaR value of the futures market.

Research Based on the CoVaR Model. Under the premise of a certain market risk, CoVaR model is used to study the value of conditional risk in other markets. Rong Wang (2016) [8] adopted commercial banks for empirical, the conditional value at risk, CoVaR model using the data of 16 listed commercial banks in China on commercial banks two-way spillover effects of systemic risk estimation model. The research showed that the systemic risk of commercial banks had obvious positive two-way spillovers.

Research Based on the Copula Model. Hu (2002) [9] for the first time, put forward the concept of mixed copulas connect function, by building a hybrid copulas connect function to research and analyzing the relationship between financial variables, hybrid copulas connect functions closely was found between degree of dependence and the dependent variable. Weiwei Zhang and Xiangin Tang (2016) [10] used copulas connect model to measure the joint distribution of the stock index futures and spot, according to the rates of the two data time-varying copulas connect function was used to measure the dynamic correlation between the two. By analyzing the time sequence diagram of the dynamic correlation coefficient, it was found that the futures spot market was indeed highly correlated, showed the continuity and the thick tail characteristics.

\section{Research Status of Risk Spillover Effect in Futures Market}

At present, the domestic and foreign scholars in the financial markets in the study of financial risk spillover mainly concentrate in the stock, bond market and bank, and overflow of futures in the field of risk study is relatively small, research on iron ore futures market is insufficient. Xu and Fung (2005) [11] applied the ARCH model to study the risk spillovers between Japanese and U.S. metals 
futures markets, and found that prices fluctuate between the two cities. Li (2015) [12] through the establishment of the VAR-BEKK bivariate GARCH model to study the csi 300 futures and spot market volatility spillover effect, the empirical shows that the csi 300 futures and spot markets exist two-way volatility spillover effect, while the former influence is in a more obvious way.

Domestic scholars have also conducted extensive research on the spillover effects of the futures market. Qingfu Liu and Haimin Wang (2006) [13] used EGARCH model to study China's soybean futures and the spot market, the volatility spillover effect between China's soybean futures and spot prices exist two-way causality. Haixia Wu, Jing Wang (2012) [14] used BEKK GARCH model, and studied the volatility spillover effect between the spot market for agricultural products in China, the results showed that soybean on wheat has single volatility spillover effect on corn. Wenke Li (2011) [15], Wanzhu Pan (2013) [16] found the lack of iron ore pricing power in China and done some research and analysis, and put forward the countermeasures and suggestions to promote China's iron and steel enterprises overseas iron ore pricing power. Xiange Li and Yingheng Zhou (2014) [17] based on MGARCH model to study the soybean futures markets, China and the United States, Hong Kong and the risk between the spillover effect, the empirical showed that Dalian commodity exchange and soybean futures exchange and the Chicago board of trade between Tokyo and Tokyo soybean futures exchange was bidirectional volatility spillover effect.

\section{Conclusion and Prospect}

Firstly, the research achievements throughout the domestic and foreign scholars about the financial risk of overflow, can be found that the research methods used is more and more advanced, from the VaR model and Granger causality test, to the application of GARCH kind of model to CoVaR and the combination of copulas connect model. Research also refine to the various financial market, from the stock market to the foreign exchange market to the financial derivatives market, and the research of futures market risk spillover effect is relatively small for iron ore futures market risk spillover effects of study hardly.

Secondly, the correlation analysis method of financial risk overflow mainly includes linear correlation analysis, Granger causality test model, GARCH class model, CoVaR model and copula model. The research achievements of domestic and foreign scholars about risk spillover effect mainly have the above five types, and most use VaR model, Granger causality test model and GARCH model, three kinds of using CoVaR and copulas connect relatively few research results of the model. The reason is that the $\mathrm{VaR}$ model represents the maximum loss of a financial asset or market in the future, only for the risk measurement of a financial asset or market. Granger causality can only test qualitatively whether there is a risk transfer between two variables, but not quantitative calculation. The application of GARCH model requires that the marginal distribution of financial variables be distributed or normal distribution. The copula model can accurately describe the asymmetric correlation and peak thick tail characteristics of financial variables, and successfully overcome the strict requirements of traditional correlation measurement.

Thirdly, the existing domestic and foreign risk spillovers can only be concentrate in the stock market and stock index futures, and the study of risk spillover between commodity futures is relatively insufficient. By building a hybrid copula model to study the correlation and volatility of financial markets, there is little in the way of calculating the risk overflows and the correlation analysis by constructing a hybrid Copula model.

Fourthly, in this paper, on the basis of predecessors' study mixed time-varying copulas connect model is put forward, to overcome the shortage of the traditional correlation measurement method and the traditional break through the limitations of single copulas connect function, and applied to the calculation of $\mathrm{CoVaR}$ measures, providing the flexibility to capture the dynamic between financial variables, asymmetric complex dependency relationship, in order to effectively measure the risk of overflow level between domestic and international iron ore market. First proposed in this paper will be using copulas connect model calculates the CoVaR value between financial time series that is applied to risk spillover and iron ore pricing power effect research, has certain theoretical and practical significance, and has certain innovative, behind a lot and in-depth research 
is worth doing.

\section{References}

[1] William John. How to Profit from Commodity Futures Trading. Tianjin: Tianjin Academy of Social Sciences Press, 2012.128-144.

[2] Vincenzo Russo. Autoregressive Conditional Moments in VaR Estimate with Gram-Charlier and Cornish-Fisher Expansions. International Journal of Risk Assessment and Management, 2009, 11(1),67-68.

[3] N. Du and G.W. Zhang. Empirical Study on the Discovery Function of Soybean Futures Based on VaR Model. China Collective Economy, 2014, 4,1008-1283. (In Chinese)

[4] Namita Rajput, Parul Chopra and Ajay Rajput. FII and Its Impact on Stock Market: A Study on Lead-Lag and Volatility Spillover. Asian Journal of Finance and Accounting, 2012,4(2),18-38.

[5] Y.T. Pu. A study on the Spillover Effect of Non-ferrous Metal Futures Market and Stock Market in China. Gansu Finance, 2016, 458-64. (In Chinese)

[6] Perry Sadorsky. Correlations and Volatility Spillovers Between Oil Prices and the Stock Prices of Clean Energy and Technology Companies. Energy Economics, 2012,34(1),248-255.

[7] Z.X. Wu, B.L. Wan and S.P. Wang. Based on Different Distribution EGARCH Model of Euets Price Fluctuation and Risk Research. Practice and Cognition of Mathematics, 2014, 24, 8-14. (In Chinese)

[8] R. Wang. The Bidirectional Spillover Effect of Financial Systemic Risk and Its CoVaR Model Estimation. Statistics and Decision, 2016, 2,146-148. (In Chinese)

[9] G. Wei and T.Z. Hu. Super modular Dependence Ordering on a Class of Multivariate Copulas. Statistics and Probability Letters, 2002,57(4),375-385. (In Chinese)

[10] W.W. Zhang and X.J. Tang. Research on the Dynamic Correlation Between China Stock Index Futures and Spot Market Based on Time-varying Copula. Technology Innovation and Application, 2014, 445. (In Chinese)

[11] X.E. Xu and H.G. Fung. Cross-Market Lingkages between US and Japanese Precious Metals Futures Trading. Journal of International Financial Markets, 2005,15,107-124.

[12] S.Y. Li. Volatility Spillovers in the CSI300 Futures and Spot Markets in China: Empirical Study Based on Discrete Wavelet Transform and VAR-BEKK-bivariate GARCH Model. Procedia Computer Science, 2015,55,380-387. (In Chinese)

[13] Q.F. Liu and H.M. Wang. Price Research between Futures Market and Spot MarketExperience of China's Agricultural Market. Financial Research, 2006, 444-51. (In Chinese)

[14] H.X. Wu and J. Wang. Research on the Spillover Effects of Grain Market Prices in China. Agricultural Technology Economy, 2012 (10), 14-21.

[15] W.K. Li. International Pricing Power of Iron Ore is Reconstructed and China's Countermeasures. China economic trade, 2011, 2. (In Chinese)

[16] W.Z. Pan. The Reason for the Lack of Pricing Power of Iron Ore Trading in China. Charming China, 2013,26. (In Chinese)

[17] X.G. Li and Y.H. Zhou. Analysis of Volatility Spillover Effect of China and International Soybean Futures Market. Technical Economy and Management Research, 2014 (6), 103-107. (In Chinese) 